\title{
Incidence of blood-related work accidents among health workers in a government hospital in Benin City, Nigeria
}

\author{
AN Ofilia ${ }^{a}$ MC Asuzu ${ }^{b}$ and $\mathrm{OH}$ Okojie ${ }^{a}$
}

\begin{abstract}
Accidents are hazards to which health workers are exposed. Hazards may be physical, chemical, biological, mechanical or psychosocial. Mechanical hazards are very common in the health industry because of the frequent use of pointed and sharp instruments such as needles, scalpel and knives. This six-month (June 1999 and June 2000) longitudinal incidence study was carried out at the Central Hospital, Benin City, Nigeria, as a follow-up on a previous cross-sectional study on frequency of blood-related work accidents in the same hospital. All the doctors, laboratory workers and $50 \%$ of nurses were included in the study. The nurses were selected using stratified random sampling method. Two hundred and fourteen health care workers started the follow-up study, out of which 146 were left at the end of the six-month period, giving an attrition rate of $31.8 \%$. Results shows that contact with patients' blood with ungloved hands, blood splashes on the face and other parts of the body, needle pricks, cuts from drug ampoules and glove perforation during surgery were the major work-related accidents/injuries during the six-month follow-up. This is similar to findings from the retrospective study. The frequencies of various accidents were higher during the six-month follow-up (incidence study) than the six months prior to the study (retrospective study). Combining all the health workers, the incidence densities of these five major work-related accidents were between 3.6 per person years (ppy) to 9.5ppy. These incidence densities were all significantly higher for doctors than nurses or laboratory workers. There is an urgent need to reduce the incidence of these work-related accidents/injuries in order to reduce the chances of health workers developing occupationally acquired diseases.
\end{abstract}

KEY WoRDS: Incidence, blood, work accidents, health workers

${ }^{a}$ Department of Community Health, School of Medicine, College of Medical Sciences, University of Benin, PMB 1154, Benin City, Nigeria. ${ }^{b}$ Department of Community Medicine, University College Hospital, PMB 5116, Ibadan, Oyo-State, Nigeria.

Correspondence: Dr (Mrs.) A. N. Ofili, Department of Community Health, School of Medicine, College of Medical Sciences, University of Benin, PMB 1154, Benin City, Nigeria. E-mail: aofili13@yahoo.com

\section{INTRODUCTION}

Accidents are hazards to which health workers are exposed. A health hazard is a material substance or circumstance that poses a danger to human health. ${ }^{1}$ Hazards may be physical, chemical, biological, mechanical or psychosocial. Examples of hazards that hospital workers face are physical hazards such as radiation, leading to sickness, burns and cancers; hazards from chemicals, leading to contact dermatitis and allergic asthma; 
psychological hazards, which may result from worker-worker relationship, worker-management group relationship and line management (boss-subordinate) relationships. These relationships determine and contribute a lot to job satisfaction as a result of their effects on efficiency and productivity at work, conditions of work, social justice in terms of just promotion at work and other deserved recognition for work done. ${ }^{1}$ Managers who are unable to keep their personal problems to themselves but rather come to take it out on their juniors or subordinates at the work place form a psychosocial occupational hazard. ${ }^{1}$ This is very common in many women job situations. ${ }^{2}$

Mechanical hazards are very common in the health industry because of the frequent use of pointed and sharp instruments as needles, scalpel and knives. This results in injuries that expose the workers to bloodborne diseases (biological hazards). This study focuses on the mechanical hazards that expose workers to blood-borne diseases such as AIDS and hepatitis B. These have been the most devastating infections that a worker may acquire from his workplace.

Other diseases that can be acquired as a result of occupational exposures to blood include malaria, ${ }^{2}$ tuberculosis, ${ }^{3}$ rocky mountain spotted fever, ${ }^{4}$ herpes zoster, ${ }^{5}$ lassa fever, ${ }^{6}$ cryptococcus, ${ }^{7}$ non-A-non-B hepatitis ${ }^{8}$ and hepatitis A. ${ }^{9}$ The risk of health workers acquiring these diseases increases with increase in incidence of the mechanical hazards.

There are different types of accidental injuries in the health industry but needle stick injury remains the commonest of all. ${ }^{10}$ Marcus and co-workers in their study of 1201 health care workers exposed to blood from patients infected with HIV or patient's meeting the Center for Disease Control case definition of AIDS found that 962 (80\%) received needle stick injuries, 103 (8\%) were cut with sharp objects and 79 (7\%) had contaminated mucus membranes. ${ }^{11}$
Tokars and co-workers ${ }^{12}$ in a nine-month prospective study that was carried out in four hospitals to determine the number and circumstances of percutaneous injuries (e.g, needle stick, cuts) occurring during surgical procedures in 1990, reported 99 injuries during 95 (6.9\%) of the 1382 procedures. Suture needles caused 76 (77\%) of these 99 injuries. Three injuries (3\%) each were caused by bones, scalpels and wire. Two (2\%) of the injuries were caused by suture thread, and one (1\%) each by a bone fragment, bone hook, orthopaedic pin, cannula, retractor, scissors, staple gun and trocar. The causes of four injuries were unknown. Two injuries were caused by suture needle placed on the surgical field while not in use. Seventy per cent of the injuries were related to suturing. ${ }^{12}$

One hundred and fifty of a cohort of 531 health care workers followed up in the United States of America reported percutaneous or mucous membrane exposure to blood or body fluids from a patient with AIDS during the treatment of 238 of such patients. ${ }^{8}$

Momah $^{13}$ in her study of the epidemiology of needle stick and sharp injuries among health care workers in Nigerian hospitals found that $84.2 \%$ of the respondents had experienced at least one injury since embarking on their respective careers, while $62.2 \%$ of them sustained their recent injury within the past one year. Doctors and nurses from two hospitals were followed up for two three-monthly periods to ascertain the occurrence of injuries ${ }^{13}$ and the survey revealed high incidence rate of 3.9 per person years (ppy) and 2.2 ppy for the first and second quarters respectively. Doctors in the surgical specialities and house officers had the highest rate. $^{13}$

A study carried out in Tanzania showed an incidence rate of five per health care worker per year of percutaneous injuries. ${ }^{14}$ The incidence of needle stick injuries among 8645 health care workers from teaching hospitals in Taiwan was 1.30ppy and injuries 
from other sharp objects was found to be 1.21 ppy. ${ }^{15}$ This six-month prospective study set out to explore the trend of these injuries at the Central Hospital, Benin City, Nigeria.

\section{MATERIALS AND METHODS}

This study was conducted from June 1999 to June 2000 at the Central Hospital, Benin City, Nigeria, which is the largest health industry under the Edo State Hospitals Management Board. It has a large population of health personnel. The study design was a six-month longitudinal incidence study. This was a follow-up on a previous cross-sectional study on frequency of blood-related work accidents in Central Hospital. All doctors and laboratory workers were included in the study, while $50 \%$ of the nurses were included based on the sample size calculation for comparative purposes. The nurses were selected using stratified random sampling method. The nursing population was divided into groups or strata based on speciality practice areas at the hospital such as paediatrics, surgery, medicine, casualty and theatre.

A structured questionnaire was designed and used to obtain information on the incidence of occupational accidents among the three groups of health care workers over the six-month period. The questionnaire was self-administered every two weeks to the same cohort of hospital workers through their heads of departments or wards for the period. Pre-testing of questionnaire was carried out at the University of Benin Teaching Hospital, Benin City, which is a government tertiary hospital like the Central Hospital. The University of Benin Teaching Hospital ethical committee approved the study, while informed consent was obtained from the medical director of the Central Hospital. Respondents were informed that their responses would be held in strict confidence. Thus, eligibility to participate in the study was based on their willingness to take part.
Two hundred and fourteen health care workers (127 nurses, 53 doctors and 34 laboratory workers) started the follow-up study. However, at the end of the study, 146 health care workers were left, giving an attrition rate of $31.8 \%(n=68)$. The time at risk during the six-month follow-up period was 52.1 person years, 21.1 person years, 13.6 person years and 86.9 person years for nurses, doctors, laboratory workers and all health workers respectively.

\section{RESULTS}

A total of 214 hospital workers (doctors, nurses and laboratory workers) at the Central Hospital, Benin City, started the follow-up study. This was made up of $53(24.8 \%)$ doctors, 127 (59.3\%) nurses and 34 (15.9\%) laboratory workers (Table 1).

The frequencies of various work-related accidents/injuries that occurred during the six-month period are shown in Tables 2, 3, 4 and 5 .

The major accidents/injuries at work among the nurses during the study were contact with patient's blood with ungloved hands, blood splashes on face and other parts of the body, needle pricks, cuts from drug ampoules, glove perforation during surgery and assault by violent/aggressive patient. The incidence of cutaneous exposures was higher than parenteral exposures (Table 2).

The major accidents/injuries at work among the doctors in the study were contact with blood with ungloved hands, blood splashes on the face and other parts of the body, needle pricks, glove perforation during surgery and cuts from drug ampoules. Like the nurses, cutaneous exposures were commoner than parenteral exposures (Table 3).

The major accidents/injuries at work among the laboratory workers were contact with patient's blood with ungloved hands, blood splashes on face and parts of the body, needle pricks and chemical splashes (Table 4). 
Table 1 Duration of exposure of respondents to risk of occupational accidents

\begin{tabular}{|c|c|c|c|c|c|c|}
\hline $\begin{array}{l}\text { Time at risk } \\
\text { (months) }\end{array}$ & $\begin{array}{l}\text { No. of } \\
\text { nurses }\end{array}$ & $\begin{array}{r}\text { Total time } \\
\text { at risk } \\
\text { (months) }\end{array}$ & $\begin{array}{r}\text { No. of } \\
\text { doctors }\end{array}$ & $\begin{array}{r}\text { Total time } \\
\text { at risk } \\
\text { (months) }\end{array}$ & $\begin{array}{r}\text { No. of lab } \\
\text { workers }\end{array}$ & $\begin{array}{r}\text { Total time } \\
\text { at risk } \\
\text { (months) }\end{array}$ \\
\hline$\overline{6}$ & 92 & 552 & 32 & 192 & 22 & $\overline{132}$ \\
\hline 5.5 & - & - & 1 & 5.5 & 1 & 5.5 \\
\hline 5 & 5 & 25 & 2 & 10 & - & - \\
\hline 4.5 & 3 & 13.5 & 5 & 22.5 & 1 & 4.5 \\
\hline 4 & - & - & - & - & - & - \\
\hline 3.5 & 2 & 7 & - & - & 1 & 3.5 \\
\hline 3 & 2 & 6 & 1 & 3 & - & - \\
\hline 2.5 & - & - & 2 & 5 & 1 & 2.5 \\
\hline 2 & 2 & 4 & 3 & 6 & 8 & 16 \\
\hline 1.5 & 3 & 4.5 & 6 & 9 & - & - \\
\hline 1 & 9 & 9 & - & - & - & - \\
\hline 0.5 & 9 & 4.5 & 1 & 0.5 & - & - \\
\hline Total & 127 & 625.5 & 53 & 253.5 & 34 & 164 \\
\hline
\end{tabular}

Table 2 Work-related accidents/injuries among nurses during the follow-up study

\begin{tabular}{lrrrr}
\hline Work-related accident/injury & $\begin{array}{r}\text { No. of } \\
\text { cases }\end{array}$ & $\begin{array}{r}\text { Total no. } \\
\text { of } \\
\text { accidents }\end{array}$ & $\begin{array}{r}\text { Mean } \\
\text { frequency }\end{array}$ & $\begin{array}{r}\text { Incidence } \\
\text { density } \\
\text { (ppy) }\end{array}$ \\
\hline Contact with patient's blood with ungloved hands & 420 & 1014 & 6.5 & 8.1 \\
Blood splashes on the face and other parts of the & & & & 5.6 \\
body & 294 & 705 & 4.6 & 4.5 \\
Needle pricks & 237 & 321 & 1.0 & 4.1 \\
Cuts from drug ampoules & 213 & 342 & 2.2 & 2.9 \\
Glove perforation during surgery & 153 & 510 & 3.3 & 2.6 \\
Assault by violent/aggressive patient & 138 & 399 & 2.6 & 1.4 \\
Knife cuts & 75 & 132 & 0.9 & 1.2 \\
Chemical splashes & 60 & 399 & 2.6 & 0.9 \\
Electric shock (at work) & 48 & 87 & 0.6 & 0.6 \\
Accidental falls (at work) & 30 & 33 & 0.2 & 0.4 \\
Scalpel injury & 21 & 26 & 0.2 & 0.4 \\
Open wound contamination with patient's blood & 21 & 24 & 0.2 & 0.3 \\
Fire accidents & 18 & 33 & 0.2 & 0.3 \\
Diathermy & 15 & 15 & 0.1 & \\
\hline ppy = per person year; Person years of observation $=52.1$ person year (during 6 months period)
\end{tabular}

Combining all health workers, contact with patient's blood with ungloved hands, blood splashes on the face and other parts of the body, needle pricks, cuts from drug ampoules and glove perforation during surgery were the major work-related accidents or injuries during the study (Table 5). 
Table 3 Work-related accidents/injuries among doctors during six months follow-up study

\begin{tabular}{lrrrr}
\hline Work-related accident/injury & $\begin{array}{r}\text { No. of } \\
\text { cases }\end{array}$ & $\begin{array}{r}\text { Total no. } \\
\text { accidents } \\
\text { of }\end{array}$ & $\begin{array}{r}\text { Mean } \\
\text { frequency }\end{array}$ & $\begin{array}{r}\text { Incidence } \\
\text { density } \\
\text { (ppy) }\end{array}$ \\
\hline Contact with patient's blood with ungloved hands. & 299 & 1164 & 22.0 & 14.2 \\
Blood splashes on the face and other parts of the & & & & \\
body & 297 & 945 & 17.8 & 14.1 \\
Needle pricks & 150 & 384 & 7.2 & 7.1 \\
Glove perforation during surgery & 144 & 468 & 8.8 & 6.8 \\
Cuts from drug ampoules & 134 & 426 & 8.0 & 6.3 \\
Open wound contamination with patients blood & 30 & 135 & 2.6 & 1.4 \\
Scalpel injury & 27 & 39 & 0.7 & 1.3 \\
Electric shock (at work) & 21 & 30 & 0.6 & 1.0 \\
Chemical splashes & 21 & 63 & 1.2 & 1.0 \\
Assault by violent/aggressive patient & 18 & 24 & 0.5 & 0.9 \\
Knife cuts & 9 & 12 & 0.2 & 0.4 \\
Diathermy & 6 & 6 & 0.1 & 0.3 \\
Accidental falls (at work) & 6 & 6 & 0.1 & 0.3 \\
Fire accidents & 1 & 1 & 0.01 & 0.05 \\
\hline
\end{tabular}

$\overline{\text { ppy }}=$ per person year; Person years of observation $=21.1$ person year (during 6 months period)

Table 4 Work-related accidents/injuries among laboratory workers during six months follow-up study

\begin{tabular}{lrrrr}
\hline Work-related accident/injury & $\begin{array}{r}\text { No. of } \\
\text { cases }\end{array}$ & $\begin{array}{r}\text { Total no. } \\
\text { of } \\
\text { accdents }\end{array}$ & $\begin{array}{r}\text { Mean } \\
\text { frequency }\end{array}$ & $\begin{array}{r}\text { Incidence } \\
\text { density } \\
\text { (ppy) }\end{array}$ \\
\hline Contact with patient's blood with ungloved hands & 104 & 384 & 11.3 & 7.6 \\
Blood splashes on the face and other parts of the & & & & 4.4 \\
body & 60 & 96 & 2.8 & 2.9 \\
Needle pricks & 40 & 40 & 1.2 & 2.0 \\
Chemical splashes & 28 & 36 & 1.1 & 1.2 \\
Electric shock (at work) & 16 & 20 & 0.6 & 12 \\
Assault by violent/aggressive patient & 16 & 24 & 0.7 & 1.2 \\
Knife cuts & 16 & 16 & 0.5 & 0.9 \\
Glove perforation during surgery & 12 & 16 & 0.5 & 0.9 \\
Scalpel injury & 12 & 12 & 0.4 & 0.6 \\
Open wound contamination with patients blood & 8 & 16 & 0.5 & 0.6 \\
Accidental falls (at work) & 8 & 16 & 0.5 & 0.3 \\
Fire accidents & 4 & 4 & 0.1 & \\
\hline
\end{tabular}

$\overline{p p y}=$ per person year; Person years of observation $=13.7$ person year (during 6 months period) 
Table 5 Work-related accidents/injuries during six months follow-up study among all health workers

\begin{tabular}{lrrrr}
\hline Work-related accidents/injuries & $\begin{array}{r}\text { No. of } \\
\text { cases }\end{array}$ & $\begin{array}{r}\text { Total no. } \\
\text { of } \\
\text { accidents }\end{array}$ & $\begin{array}{r}\text { Mean } \\
\text { frequency }\end{array}$ & $\begin{array}{r}\text { Incidence } \\
\text { density } \\
\text { (ppy) }\end{array}$ \\
\hline Contact with patient's blood with ungloved hands & 823 & 2567 & 10.6 & 9.5 \\
Blood splashes on the face and other parts of the & & & 7.2 & 7.5 \\
body & 651 & 1746 & 3.1 & 4.9 \\
Needle pricks & 427 & 745 & 3.2 & 4.0 \\
Cuts from drug ampoules & 347 & 768 & 4.1 & 3.6 \\
Glove perforation during surgery & 309 & 994 & 1.9 & 2.0 \\
Assault by violent/aggressive patient & 172 & 447 & 2.1 & 1.3 \\
Chemical splashes & 109 & 498 & 0.6 & 1.2 \\
Knife cuts & 100 & 148 & 0.6 & 1.0 \\
Electric shock (at work) & 85 & 137 & 0.3 & 0.7 \\
Scalpel injury & 60 & 77 & 0.7 & 0.7 \\
Open wound contamination with patients blood & 59 & 175 & 0.2 & 0.5 \\
Accidental falls (at work) & 44 & 55 & 0.1 & 0.3 \\
Fire accidents & 23 & 38 & 0.1 & 0.3 \\
Diathermy & 21 & 21 & 0.3 \\
\hline
\end{tabular}

ppy = per person year; Person years of observation (during 6 months period) $=86.9$ person year

\section{DISCUSSION}

The five major work-related accidents/injuries for the doctors, nurses and laboratory workers during the follow-up study were the same as those in the retrospective study ${ }^{16}$ (Tables 2, 3 and 4). Combining all the health workers, the five major work-related accidents/injuries during the study also remained the same as those of the earlier study ${ }^{16}$ (Table 5 ).

The most frequent work-related accidents at work among all the health workers were the same with findings from the retrospective study. ${ }^{16}$ This indicates that the incidence of cutaneous exposures was higher than parenteral exposures. The incidence densities of contact with patient's blood with ungloved hands were 8.1ppy, 14.2ppy, 7.6ppy and 9.5ppy for nurses, doctors, laboratory workers and all health workers respectively. This shows a high incidence rate. The doctors had a significantly higher incidence density than nurses $(Z=7.554 ; p=0.000[4.22 E-14])$ and laboratory workers $(\mathrm{Z}=5.572 ; \mathrm{p}=0.000$ [2.51E-08]).

The incidence densities of blood splashes on face and other parts of the body were also high; these were 5.6ppy, 14.1ppy, 4.4ppy and 7.5ppy for nurses, doctors, laboratory workers and all health workers respectively. Again, doctors had a significantly higher incidence density of blood splashes on the face and other parts of the body than nurses $(Z=4.315$; $p=0.000[1.30 \mathrm{E}-30])$ and laboratory workers $(\mathrm{Z}=8.725 ; \mathrm{p}=0.000$ [2.66E-18]).

Needle pricks (4.9ppy) ranked third of the work-related accidents/injuries among all health workers (Table 5) during the followup study. It occurred in 745 respondents, hence making it the commonest cause of percutaneous injury. This is similar to results from the previous study and various earlier studies. ${ }^{10,17,18}$ Momah, ${ }^{13}$ in her study of two hospitals, where she followed doctors and nurses for two three-monthly periods to 
ascertain the occurrence of injuries, found the incidence rates of needle stick and sharp injuries to be 3.9ppy and 2.2ppy for the first and second quarters respectively. A study among health workers in teaching hospitals in Taiwan found the incidence of needle prick to be 1.30ppy and 1.21ppy for other sharp objects. These values are lower than those found in this study. The doctors had a significantly higher incidence density for needle pricks than nurses $(Z=4.315 ; p=0.000$ [1.60E-05]) and laboratory workers $(\mathrm{Z}=$ 5.167; $\mathrm{p}=0.000$ [2.37E-07]).

Cuts from drug ampoules ranked fourth as a cause of accidents/injuries among all the health workers (4.0ppy) during the six months follow-up, similar to previous study. The doctors had a significantly higher incidence density than nurses $(Z=4.027$; $p=0.000$ [5.65E-05]) for cuts from drug ampoules.

Glove perforation during surgery ranked fifth as a cause of accidents/injuries among health workers (3.6ppy) during the six months follow-up. Doctors had a significantly higher incidence density for glove perforation during surgery than nurses $(Z=7.480 ; p=0.000$ [7.43E-14]).

Generally, the frequencies of various accidents were higher during the six months follow-up than the previous six months study. This difference may be attributed to problems of memory recall. The incidence densities of the five major work-related accidents were higher for doctors than other health workers, similar to findings from the retrospective study. The implications of this is that doctors were more exposed to these accidents and, hence, are likely to have a higher risk of acquiring blood-borne infections at work.

There is an urgent need to reduce the incidence of these work-related accidents/ injuries through training programmes and seminars for health workers. This will help to reduce their chances of acquiring occupational diseases such as HIV/AIDS and hepatitis $\mathrm{B}$. There is also a need to institute effective reporting system in hospitals through the staff clinics.

\section{ACKNOWLEDGEMENT}

The authors are grateful to all the hospital workers at the Central Hospital, Benin City, for their co-operation during data collection.

\section{References}

1. Asuzu MC. Occupational Health: A Summary Introduction and Outline of Principles. 1st Edition. Ibadan: Africa-Link Books, 1994, 7.

2. Cannon NJ, Walker SP and Dismukis WE. Malaria acquired by accidental needle puncture. JAMA 1972; 222(1): 1425.

3. Sahu SA and Pierson DJ. Primary cutaneous inoculation of drug resistant tuberculosis. Am J Med 1974; 57: 676-678.

4. Sexton DJ, Gallis HA, Mcrae JR and Cate TR. Possible needle associated rocky mountain spotted fever. $N$ Engl J Med 1975; 292: 645.

5. Su DWP and Muller SA. Herpes Zoster case report of possible accidental inoculation. Arch Dermatol 1976; 112: 1755-1756.

6. Focus on lassa fever and neonatal tetanus. Nig Bull Epidemiol 1993; 3(1): 1-9.

7. Glaser JB and Gordon A. Inoculation of cryptococcus without transmission of the acquired immunodeficiency syndrome. $N$ Engl J Med 1985; 313: 266.

8. Henderson DK, Saah AJ, Zak BJ, et al. Risk of nosocomial infection with human T-cell lymphotropic virus in a large cohort of intensively exposed health care worker. Ann Intern Med 1986; 104: 644-647.

9. Centers for Disease Control. Hepatitis A among drug abusers. Morbid Mortal Wkly Rep 1988; 37(19): 297-305.

10. Camilleri AE, Murray S and Imrie CW. Needle stick injury in surgeons: what is the incidence? J R Coll Surg Edinb 1991; 36: 317.

11. Marcus R. CDC co-operative needle-stick surveillance group. Surveillance of health care workers exposed to blood infected with HIV. $N$ Engl J Med 1988; 319: 1118-1123. 
12. Tokar JI, Bell DM, Culver DH, Marcus R, Mendelson $\mathrm{MH}$, et al. Percutaneous injuries during surgical procedures. JAMA 1992; 267: 2866-2904.

13. Momah PH. The epidemiology of needle stick and sharp injuries among health workers in Nigerian hospitals. Report of a project. Faculty of Public Health, National Postgraduate Medical College, 1992, 102.

14. WHO. Monitoring the AIDS Pandemic. The Status and Trends of the HIV/AIDS Epidemics in the World Provisional Report. Geneva: Switzerland. 1998; 17-18.

15. Guo YL, Shiao J, Chuang YC and Huang KY. Needle stick and sharp injuries among health care workers in Taiwan. Epidemiol Infect 1999; 122(2): 259-265.
16. Ofili AN. Occupational accidents among hospital workers at the Central Hospital, Benin City, Edo State, Nigeria. A dissertation accepted by the Faculty of Public Health, National Postgraduate Medical College, November 2000, 70-84.

17. Hussain SA, Latif AB and Choudhary AA. Risk to surgeons: a survey of accidental injuries during operations. Br J Surg 1988; 75: 314-316.

18. Ruthanne and the CDC Cooperative Needlestick Surveillance Group. Surveillance of health care workers exposed to blood from patients infected with the human immunodeficiency virus. $N$ Engl J Med 1988; 319(17): 1118. 